\title{
Proportional assist ventilation (PAV) versus neurally adjusted ventilator assist (NAVA): effect on oxygenation in infants with evolving or established bronchopulmonary dysplasia
}

\author{
Katie A. Hunt ${ }^{1,2} \cdot$ Theodore Dassios $^{1,3} \cdot$ Anne Greenough ${ }^{1,2,4}$ C \\ Received: 29 November 2019 / Revised: 13 January 2020 / Accepted: 15 January 2020 / Published online: 25 January 2020 \\ (C) The Author(s) 2020
}

\begin{abstract}
Both proportional assist ventilation (PAV) and neurally adjusted ventilatory assist (NAVA) provide pressure support synchronised throughout the respiratory cycle proportional to the patient's respiratory demand. Our aim was to compare the effect of these two modes on oxygenation in infants with evolving or established bronchopulmonary dysplasia. Two-hour periods of PAV and NAVA were delivered in random order to 18 infants born less than 32 weeks of gestation. Quasi oxygenation indices ("OI") and alveolararterial ("A-a") oxygen gradients at the end of each period on PAV, NAVA and baseline ventilation were calculated using capillary blood samples. The mean "OI" was not significantly different on PAV compared to NAVA (7.8 (standard deviation (SD) 3.2) versus 8.1 (SD 3.4), respectively, $p=0.70$, but lower on both than on baseline ventilation (mean baseline "OI" 11.0 (SD 5.0)), $p=$ 0.002, 0.004, respectively). The "A-a" oxygen gradient was higher on PAV and baseline ventilation than on NAVA (20.8 (SD 12.3) and 22.9 (SD 11.8) versus 18.5 (SD 10.8) $\mathrm{kPa}, p=0.015,<0.001$, respectively).

Conclusion: Both NAVA and PAV improved oxygenation compared to conventional ventilation. There was no significant difference in the mean "OI" between the two modes, but the mean "A-a" gradient was better on NAVA.
\end{abstract}

What is Known:

- Proportional assist ventilation (PAV) and neurally adjusted ventilatory assist (NAVA) can improve the oxygenation index (OI) in prematurely born infants.

- Both PAV and NAVA can provide support proportional to respiratory drive or demand throughout the respiratory cycle.

What is New:

- In infants with evolving or established BPD, using capillary blood samples, both PAV and NAVA compared to baseline ventilation resulted in improvement in the "OI", but there was no significant difference in the "OI" on PAV compared to NAVA.

- The "alveolar-arterial" oxygen gradient was better on NAVA compared to PAV.

Keywords Neurally adjusted ventilator assist $\cdot$ Proportional assist $\cdot$ Oxygenation index

\section{Abbreviations}

A-a Alveolar-arterial gradient

BPD Bronchopulmonary dysplasia
CPIP Chronic pulmonary insufficiency of prematurity

Edi Electromyogram of the diaphragm

$\mathrm{FiO}_{2} \quad$ Inspired oxygen concentration
Communicated by Daniele De Luca

Anne Greenough

Anne.greenough@kcl.ac.uk

Katie A. Hunt

Katie.a.hunt@kcl.ac.uk

Theodore Dassios

Theodore.dassios@kcl.ac.u
1 Women and Children's Health, School of Life Course Sciences, Faculty of Life Sciences and Medicine, King's College London, London, UK

2 The Asthma UK Centre in Allergic Mechanisms of Asthma, Kings College London, London, UK

3 Neonatal Intensive Care Centre, King's College Hospital NHS Foundation Trust, London, UK

4 NIHR Biomedical Research Centre, Guy's and St Thomas' NHS Foundation Trust, King's College London, London, UK 
MAP Mean airway pressure

NAVA Neurally adjusted ventilatory assist

OI Oxygenation index

PAV Proportional assist ventilation

PEEP Positive end-expiratory pressure

PIP Peak inspiratory pressure

PRVC Pressure-regulated volume control

VTe Expiratory tidal volume

\section{Introduction}

Mechanical ventilation can be live-saving in the neonatal period but is also associated with complications such as bronchopulmonary dysplasia (BPD) and chronic respiratory morbidity [1]. Modes of ventilation that allow synchrony both of the timing and the level of support to the infant's respiratory effort have been developed. Both proportional assist ventilation (PAV) and neurally adjusted ventilator assist (NAVA) provide support synchronised throughout the respiratory cycle. PAV delivers support proportional to the infant's respiratory effort. Inspiratory pressure can be delivered in proportion to the change in flow (resistive unloading) and the change in tidal volume (elastic unloading), and the clinician can adjust the amount of unloading used [2]. The support delivered by NAVA is proportional to the electrical activity of the diaphragm, which is reflective of the neural respiratory drive. NAVA uses a specialised nasogastric tube with an electrode array at the distal end which detects the electromyogram of the diaphragm (Edi). The Edi is the signal used to trigger the ventilator and determines the level of support. The delivered pressure throughout each inflation is in proportion to the Edi signal. The clinician can adjust the NAVA level to increase or decrease the amount of pressure delivered per microvolt of Edi detected [3, 4].

The results of short-term studies [5-15] suggest that both PAV and NAVA improved oxygenation and were associated with lower airway pressures compared to conventional or other triggered modes of ventilation in prematurely born infants with evolving BPD, otherwise known as chronic pulmonary insufficiency of prematurity (CPIP) [16]. There are no studies in that population comparing PAV and NAVA, and hence the aim of this study was to compare the effect of PAV and NAVA on the oxygenation index in infants with evolving or established BPD. It has been demonstrated in an in vitro study that PAV was associated with a relatively long trigger delay [17]. In studies in adults, longer trigger delays have been found with PAV compared to NAVA $[18,19]$. Hence, we hypothesised that NAVA would be associated with a superior (i.e. lower) OI in a crossover study as more of the infant's respiratory cycle would be supported by pressure support.

\section{Methods}

Infants were recruited from the tertiary neonatal unit at King's College Hospital NHS Foundation Trust between June 2017 and July 2018. Infants were eligible for the study if they were born at a gestational age of less than 32 weeks and remained ventilated at or beyond 1 week after birth, that is, they had evolving or established BPD [20]. Those receiving neuromuscular blockade or with complex congenital cardiac abnormalities were excluded. The study was approved by the LondonSouth East NHS Research Ethics Committee and the Health Research Authority and prospectively registered on clinicaltrials.gov with the identifier NCT02967549. Written informed parental consent was obtained.

Infants were routinely ventilated via shouldered Coles endotracheal tubes (Portex, Smith Medical, Hythe, UK) which have been shown to have minimal to no leak [21]. Prior to entry into the study, the infants were ventilated using SLE 5000 or 6000 ventilators (Specialised Laboratory Equipment, Croydon, UK) in assist control (A/C) or synchronised intermittent mandatory ventilation (SIMV) modes. Volume targeting was preferentially used, with target tidal volumes between 5 and $7 \mathrm{ml} / \mathrm{kg}$ as per the Unit's guidelines. Some clinicians, however, preferred to use pressurelimited ventilation. During the study, the infants were transferred to either the Servo-n ventilator (Maquet Critical Care, Solna, Sweden) or the Stephanie ventilator (Stephan GMBH, Gackenbach, Germany) depending on whether they had been randomised to receive first NAVA or PAV. The ventilator circuits were changed according to ventilator type. The randomisation sequence was generated with a random number generator and allocations concealed inside opaque, sealed and consecutively numbered envelopes. Infants received ventilation at their baseline settings on either ventilator, followed by $2 \mathrm{~h}$ of either NAVA or PAV. At the end of the 2-hour period, a blood gas was taken, and the infant was transferred to the other study ventilator, following which the above sequence was repeated, that is, $1 \mathrm{~h}$ on their baseline settings and $2 \mathrm{~h}$ on the study mode. Infants were monitored throughout, and the heart rate, respiratory rate and oxygen saturations were recorded every $10 \mathrm{~min}$, and all desaturations less than $88 \%$ were documented.

NAVA was delivered by the Maquet Servo-n ventilator. A six French Edi catheter of appropriate length for the infant's weight (49 cm for 500-1500 g, 50 cm for 1000-2000 g) was inserted oro- or nasogastrically prior to the commencement of the study and left in place until the study was completed. The Edi catheter was positioned as per the manufacturer's guidance using the specialised tape measure in the packaging and correct position confirmed using the Edi catheter positioning guide function on the ventilator (Maquet Servo-n User Manual Version 1.1). The Edi was monitored using the Servo-n ventilator throughout the entire study, including on 
baseline settings, and whilst PAV was delivered via the Stephanie ventilator.

During NAVA, the NAVA level was set by observing the displayed pressure waveform on the ventilator during three to five breaths, whilst the infant was ventilated using their baseline settings and then adjusted so that the pressure on NAVA closely matched that delivered on baseline settings, aiming for a peak Edi of between 5 and $15 \mu \mathrm{V}$. The apnoea time was set to $2 \mathrm{~s}$ to avoid hypoventilation and the Edi trigger to $0.5 \mu \mathrm{V}$ as recommended by the manufacturer for neonatal use. The positive end-expiratory pressure (PEEP) was set at the same level as during baseline ventilation. Maximum PIP was initially limited to $5 \mathrm{cmH}_{2} \mathrm{O}$ above that set on baseline settings, as the Servo-n ventilator will not deliver pressures more than $5 \mathrm{cmH}_{2} \mathrm{O}$ below this limit. Ventilator parameters were manually collected with a single value that was expected to represent the existing stable baseline.

PAV was delivered using the Stephanie ventilator (Stephan GMBH, Gackenbach, Germany). Whilst ventilating on baseline settings, the infant's compliance was recorded from the ventilator display every $10 \mathrm{~min}$. The mean of the six results was calculated to determine the degree of elastic unloading required to return the infant's compliance to normal, that is, $2 \mathrm{ml} / \mathrm{cmH}_{2} \mathrm{O}$ [22]. Initial elastic unloading was set at $75 \%$ of that value and increased to $100 \%$ after $10 \mathrm{~min}$ if no abnormal waveforms were observed [17]. No resistive unloading was used as this can result in oscillation in the airway pressure waveform, which may inhibit diaphragm activity [23, 24]. The PEEP was set as the same level as during baseline settings.

The $\mathrm{FiO}_{2}$ was adjusted to maintain saturations between 92 and $96 \%$ as per the Unit's guidelines. Expiratory tidal volume, $\mathrm{FiO}_{2}$, respiratory rate, MAP, PIP and PEEP were recorded from the ventilator display (no PIP or PEEP is displayed during PAV). Blood gas analysis was performed using capillary samples. Capillary samples were not formally arterialised. Blood gas samples were analysed immediately using the blood gas analyser on the neonatal unit (ABL90 Flex, Radiometer, Brønshøj, Denmark).

As capillary blood samples were used, we calculated quasi OIs and alveolar-arterial oxygen gradients which we have designated "OIs" and "A-a" gradient, respectively. The primary outcome, "OI", was calculated as $\left(\mathrm{MAP} * \mathrm{FiO}_{2} * 100\right) /\left(\right.$ partial pressure of oxygen $\left(\mathrm{pO}_{2}\right)$. Secondary outcomes included the "A-a" gradient calculated as $\left(\mathrm{FiO}_{2} *\left(\mathrm{Patm}-\mathrm{pH}_{2} \mathrm{O}\right)-\left(\mathrm{PCO}_{2} / 0.8\right)-\mathrm{pO}_{2}\right)$, where Patm $=101.33 \mathrm{kPa}$ and $\mathrm{pH}_{2} \mathrm{O}=6.3 \mathrm{kPa}$; the oxygen saturation to fraction of inspired oxygen ratio (SF ratio) calculated as $\mathrm{SpO}_{2} / \mathrm{FiO}_{2}$ and the $\mathrm{PO}_{2} / \mathrm{FiO}_{2}$ ratio. In addition, the peak and tonic Edi during each epoch were obtained from the Maquet ventilator.

BPD was diagnosed as oxygen dependency for at least 28 days and as mild, moderate or severe depending on support required at 36 weeks corrected gestational age as per the NIH consensus guidelines [25].

\section{Sample size}

A sample size of 18 infants was chosen as this would allow detection of one standardised difference in the results with $80 \%$ power at the $5 \%$ significance level. In a previous study [14], we reported a difference in the mean OI of infants supported by NAVA compared to ACV was greater than 3 with a standard deviation of the infants' results being 2 . We had also reported a difference of 3 in previous studies of PAV [6, 8]. Thus, the calculated sample size would be able to detect such a difference (i.e. $\geq 3$ ) between the results on the two modes.

\section{Statistical analysis}

Results were compared from the end of each period of PAV, NAVA and conventional ventilation. Data were assessed for normality using a Shapiro-Wilk test. Normally distributed data were analysed using a one-way repeated measures ANOVA with Bonferroni correction. If the assumption of sphericity was violated, a Greenhouse-Geisser correction was applied. Non-normally distributed data were analysed using a Friedman test. Statistical analysis was carried out using IBM SPSS Statistics version 25 (IBM Corporation, Armonk, New York, USA.)

\section{Results}

Eighteen infants were studied (Table 1) (eight male, ten female). They were born at a median gestational age of 25.3 (range 23.6-30.3) weeks with median birthweight of 750 (range 454-950) grams. They were studied at a median of 20.5 (range 8-58) postnatal days. All of the infants were subsequently diagnosed with BPD; 13 had severe BPD, 3 moderate and 2 mild. Prior to the study, 15 infants were receiving volume-targeted ventilation, with target tidal volumes between 5 and $7 \mathrm{ml} / \mathrm{kg}$; the others were receiving pressurelimited ventilation. Nine infants were randomised to receive

Table 1 Baseline demographic details

\begin{tabular}{ll}
\hline $\mathrm{N}$ & 18 \\
\hline Sex (male) & 8 \\
Gestational age (weeks) & $25.3[23.6-30.3]$ \\
Birthweight (grams) & $750[454-950]$ \\
Postnatal age at study (days) & $20.5[8-58]$ \\
Weight at study (grams) & $865[700-1800]$ \\
\hline
\end{tabular}

Results are presented as median [range] 
NAVA first (Fig. 1). NAVA levels used ranged between 0.4 and 1.8 .

There was no significant difference in the mean "OI" at the end of $2 \mathrm{~h}$ on PAV compared to on NAVA (mean 7.8 (standard deviation (SD) 3.2) versus 8.1 (SD 3.4), $p=0.7$ ), but on both PAV and NAVA, the mean "OI" was significantly lower than on baseline ventilation (Table 2, Fig. 2). The $\mathrm{FiO}_{2}$ was higher on PAV than on NAVA (mean 0.39 (SD 0.15 ) versus 0.37 (SD 0.13) $p=0.024$ ) and the MAP lower on PAV than on NAVA (8.3 $\mathrm{cmH}_{2} \mathrm{O}(\mathrm{SD} 1.1)$ versus $9.0 \mathrm{cmH}_{2} \mathrm{O}(\mathrm{SD}(0.9), p=$ $0.025)$ ) (Table 2). If only those 13 infants who went on to develop severe BPD were included, the "OI" was significantly

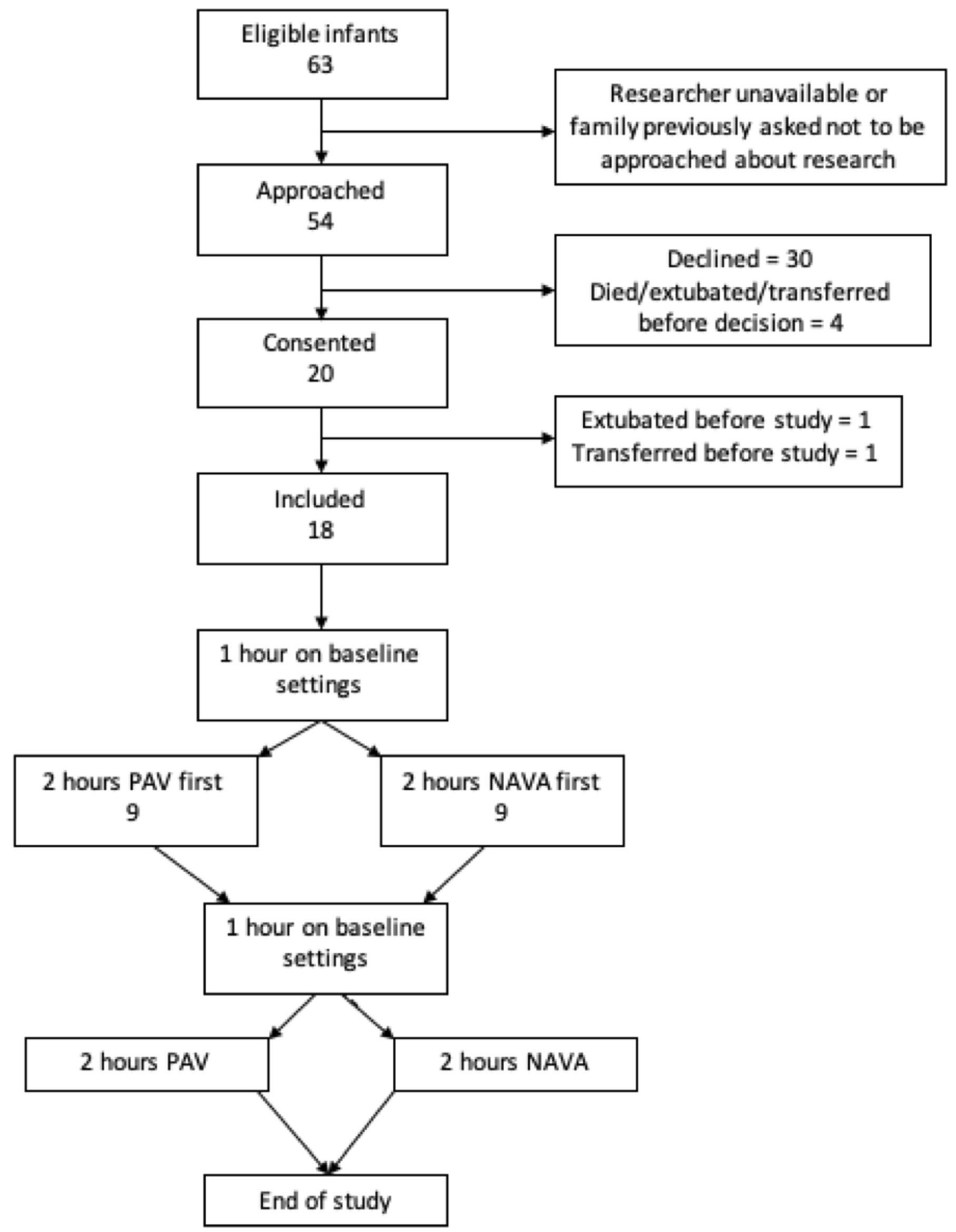

Fig. 1 Consort diagram of recruitment and study protocol 
Table 2 Comparison of ventilatory, blood gas and diaphragmatic electrical activity parameters between baseline ventilation, PAV and NAVA

\begin{tabular}{|c|c|c|c|c|c|}
\hline & Baseline & PAV & NAVA & $\mathrm{p}$ & $\begin{array}{l}\text { Pairwise } \\
\text { comparisons }\end{array}$ \\
\hline "OI" & $11.0[5.0]$ & $7.8[3.2]$ & $8.1[3.4]$ & 0.001 & $\begin{array}{l}\text { n-p } 0.70 \\
\text { b-p } 0.002 \\
\text { b-n } 0.004\end{array}$ \\
\hline $\begin{array}{l}\text { Mean airway pressure } \\
\quad\left(\mathrm{cmH}_{2} \mathrm{O}\right)\end{array}$ & $9.5[1.1]$ & $8.3[1.1]$ & $9.0[0.9]$ & $<0.001$ & $\begin{array}{l}\text { n-p } 0.025 \\
\text { b-p }<0.001 \\
\text { b-n } 0.02\end{array}$ \\
\hline $\mathrm{FiO}_{2}$ & $0.40[0.15]$ & $0.39[0.15]$ & $0.37[0.13]$ & $<0.001$ & $\begin{array}{l}\text { n-p } 0.024 \\
\text { b-p } 0.28 \\
\text { b-n } 0.003\end{array}$ \\
\hline “A-a" gradient $(\mathrm{kPa})$ & $22.9(11.8)$ & $20.8(12.3)$ & $18.4(10.8)$ & $<0.001$ & $\begin{array}{l}\text { n-p } 0.015 \\
\text { b-p } 0.127 \\
\text { b- } n<0.001\end{array}$ \\
\hline $\mathrm{SpO}_{2} / \mathrm{FiO}_{2}$ & $268[96]$ & $268[92]$ & 295 [102] & 0.002 & $\begin{array}{l}\text { n-p } 0.04 \\
\text { b-p } 1.0 \\
\text { b-n } 0.04\end{array}$ \\
\hline $\mathrm{PO}_{2} / \mathrm{FiO}_{2}$ & $104(35)$ & $120(40)$ & $126(42)$ & 0.001 & $\begin{array}{l}\text { n-p } 0.79 \\
\text { b-p } 0.033 \\
\text { b-n } 0.002\end{array}$ \\
\hline $\mathrm{PCO}_{2}[\mathrm{kPa}]$ & $8.1[1.7]$ & $8.9[1.8]$ & 8.8 [1.7] & 0.026 & $\begin{array}{l}\text { n-p } 1.0 \\
\text { b-p } 0.007 \\
\text { b-n } 0.16\end{array}$ \\
\hline $\mathrm{PO}_{2}[\mathrm{kPa}]$ & $5.4[0.76]$ & $5.66[0.68]$ & $5.6[1.0]$ & 0.69 & \\
\hline $\begin{array}{r}\text { Respiratory rate } \\
\text { (breaths } / \mathrm{min} \text { ) }\end{array}$ & $61[9]$ & $66[8]$ & $56[9]$ & 0.001 & $\begin{array}{l}\text { n-p } 0.003 \\
\text { b-p } 0.19 \\
\text { b-n } 0.093\end{array}$ \\
\hline $\begin{array}{l}\text { Expiratory tidal volume } \\
(\mathrm{ml} / \mathrm{kg})\end{array}$ & $6.2[0.7]$ & $6.4[1.0]$ & $6.5[1.2]$ & 0.32 & \\
\hline $\begin{array}{l}\text { Peak inspiratory pressure } \\
\quad\left(\mathrm{cmH}_{2} \mathrm{O}\right)^{*}\end{array}$ & $17.8[3.5]$ & & $14.3[3.0]$ & & b- $n<0.001$ \\
\hline $\begin{array}{l}\text { Positive end-expiratory } \\
\text { pressure }\left(\mathrm{cmH}_{2} \mathrm{O}\right)^{*}\end{array}$ & $5.6[4.7-7]$ & & $6[5-7]$ & & b-n 0.94 \\
\hline $\mathrm{pH}$ & $7.31[0.67]$ & $7.29[0.68]$ & $7.3[0.66]$ & 0.053 & \\
\hline $\begin{array}{l}\text { Peak electrical activity of } \\
\text { the diaphragm } \\
\text { (microvolts) }\end{array}$ & $13.6[5.8-40.4]$ & $13.1[2.4-38.4]$ & $11.3[5.2-28.5]$ & 0.33 & \\
\hline $\begin{array}{l}\text { Minimum electrical } \\
\text { activity of the } \\
\text { diaphragm (microvolts) }\end{array}$ & $2.2[0.9-4.2]$ & $2.3[0.7-4.2]$ & $2.4[0.7-4.5]$ & 0.92 & \\
\hline
\end{tabular}

Results are presented as mean (standard deviation) or median [range]

$\mathrm{n}-\mathrm{p}=$ comparison between NAVA and PAV; $\mathrm{b}-\mathrm{p}=$ comparison between baseline and PAV

$\mathrm{b}-\mathrm{n}=$ comparison between baseline and NAVA

*Data unavailable for two infants lower on NAVA or PAV than at baseline (8.4, 8.8 vs $12.8, p=$ $<0.001, p=0.023$, respectively), but the "OI" was not significantly different on PAV and NAVA $(p=0.29)$.

The "A-a" gradient was significantly higher on PAV than on NAVA (20.8 versus $18.4, p=0.015$.) It was also significantly lower on NAVA than at baseline (18.4 versus 22.9, $p<0.001$ ), but there was no statistically significant difference between PAV and baseline (20.8 versus $22.9, p=0.127$ ) (Table 2). If the 13 infants who went on to develop severe BPD were analysed separately, both PAV and NAVA were associated with lower "A-a" gradients compared to baseline ventilation (23.2 (SD 13.7) and 20.9 (SD 11.4) versus 26.5 (SD 12.1) $\mathrm{kPa}, p=0.031,0.001$, respectively), but there was no statistically significant difference between the results on 


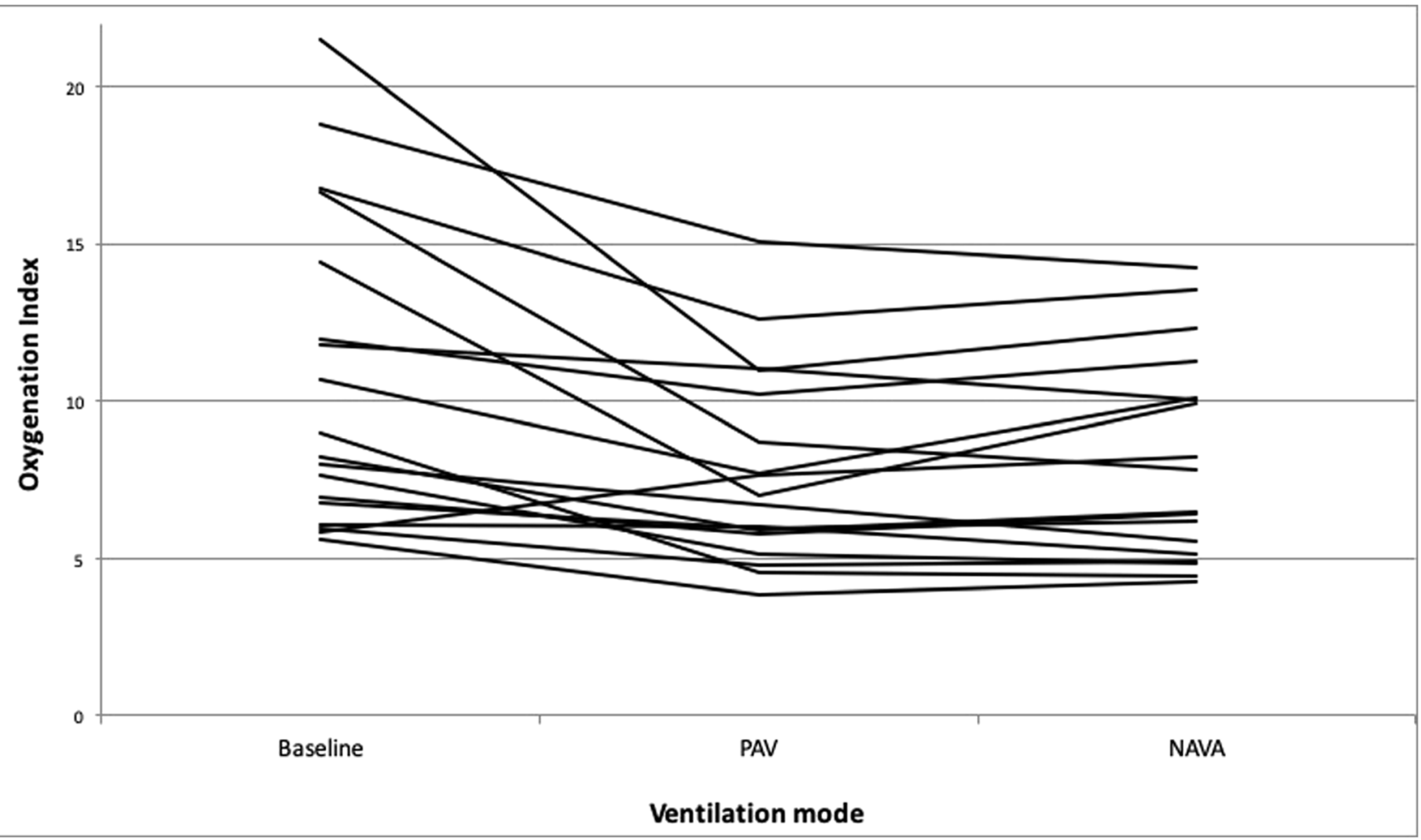

Fig. 2 "Oxygenation index" of individual infants shown by linked data points on baseline ventilation, PAV and NAVA

PAV and NAVA $(p=0.18)$. The $\mathrm{SpO}_{2} / \mathrm{FiO}_{2}$ ratio was lower on PAV and baseline than on NAVA $(p=0.004)$ (Table 2$)$. There was no significant difference in the $\mathrm{PO}_{2} / \mathrm{FiO}_{2}$ between NAVA and PAV, but both were higher than at baseline (Table 2).

There were no significant differences between the expiratory tidal volumes or the $\mathrm{pCO}_{2}$ levels on PAV compared to on NAVA (Table 2). There were no significant differences between base excess or $\mathrm{HCO}_{3}$ results on PAV and NAVA. The $\mathrm{PCO}_{2}$ was statistically significantly higher on PAV than at baseline ( 8.9 vs $8.1 \mathrm{kPa}, p=0.016$ ). The respiratory rate was significantly higher on PAV than on NAVA. The peak and minimum Edi were not significantly different between modes of ventilation (Table 2).

\section{Discussion}

We have demonstrated that there was no significant difference in mean "OI" between PAV and NAVA, but both modes resulted in a reduction in "OI" compared to baseline conventional ventilation. We used the "OI" as the primary outcome as this gives a summary of the effectiveness of each ventilator mode compared to baseline. The mean airway pressure, however, was lower and the $\mathrm{FiO}_{2}$ higher on PAV than on NAVA. As the "OI" is a composite of the MAP and $\mathrm{FiO}_{2}$, then those differences being in the opposite direction resulted in similar "OIs". The lower MAP on PAV resulted in a higher $\mathrm{FiO}_{2}$ requirement to maintain the same level of oxygenation. The lower MAP on PAV might reflect lower levels of synchrony, a different shape to the airway pressure waveform and/or a longer trigger delay [17-19]. The significantly higher "A-a" gradient (i.e. worse) on PAV compared to NAVA is consistent with the higher $\mathrm{FiO}_{2}$ requirement, as is the significantly lower $\mathrm{SpO}_{2} / \mathrm{FiO}_{2}$ (ie worse). The $\mathrm{PO}_{2} / \mathrm{FiO}_{2}$ was lower on PAV, but this did not reach statistical significance.

Both PAV and NAVA have been compared to conventional and other triggered modes of ventilation in small short-term studies in infants. PAV as compared to pressure-controlled conventional ventilation has been shown to reduce the $\mathrm{OI}$ in infants with respiratory distress syndrome [5] and to reduce the OI, peak and MAP and the work of breathing (as measured by PTPdi) in infants with evolving or established BPD [6-8]. Although there have been no randomised controlled trials of PAV in neonates, in adults, PAV versus pressure support ventilation resulted in a shorter duration of intensive care days [9]. NAVA has also been shown to have advantages over conventional ventilation in prematurely born infants. NAVA compared to pressure control ventilation and to pressurelimited synchronised intermittent mandatory ventilation (SIMV) in crossover studies, including those where infants had longer durations on each mode, resulted in lower peak inspiratory pressures (PIP) and a reduction in the work of breathing [10-13]. In prematurely born infants with evolving or established BPD, NAVA compared to 
pressure control ventilation in a crossover study resulted in reduction in the OI, MAP, $\mathrm{FiO}_{2}$ and PIP [14]. There has been one randomised controlled trial of NAVA, which was compared to pressure control ventilation and enrolled infants born between 28 and $36+6$ weeks gestational age with acute respiratory distress. There was no significant difference in the primary outcome of the duration of ventilation (35 versus $26 \mathrm{~h}, p=0.21$ ). There was also no difference in the incidence of BPD, but the study was not powered to detect this [15].

To our knowledge, there have been no previous studies in the neonatal population that have compared NAVA and PAV, but a study in adults compared NAVA and PAV to baseline pressure support ventilation [19]. The OI was not reported, but when targeting the same tidal volumes, the PIP and MAP were higher on NAVA than on PAV with comparable blood gases, although the $\mathrm{PaCO}_{2}$ was statistically significantly higher on PAV than on NAVA, as was also found in our study. The small increase in $\mathrm{PaCO}_{2}$ may be due to the way that NAVA and PAV switch to back up ventilation after an apnoea period or to the amount of unloading during PAV and the NAVA level set. If either were to be used for longer periods, then careful monitoring and adjustment of settings as required would be advised.

There are strengths and some limitations to our study. We calculated the "OI" and "A-a" gradients from capillary samples, but this was a crossover study, so each infant acted as their own control. Thus, whilst arterial samples may have been more precise, we suggest that use of capillary blood samples would not have substantially influenced our results. We did not use arterialisation of the capillary samples as there is controversy in the literature as to whether this improves the correlations with arterial results. Furthermore, capillary blood gases have been shown to correlate well with arterial gases if infants are stable and not cardiovascularly compromised [26], particularly at lower levels of arterial oxygenation as in our cohort [27]. Additionally, it has been shown that in infants with congenital diaphragmatic hernia, indices of oxygenation obtained from capillary blood gas samples and changes in these indices over time predict survival, thus suggesting that capillary oxygenation is a valid method of monitoring clinical status [28]. Nevertheless, for future studies, transcutaneous monitoring of carbon dioxide and oxygen levels could be considered. We did not assess the infants' comfort levels, and this plus assessment of the degree of asynchrony would be useful in future studies.

The NAVA level was set as per the manufacturer's guidelines. Using the manufacturer's guidelines, the MAP level during NAVA was decreased compared to baseline setting suggesting that the level was appropriate. All of the infants in our study either had or were subsequently diagnosed with BPD, indicating that our inclusion criteria successfully identified those with evolving or established BPD. The wide range of postnatal ages in our study population may have influenced our results, but advantages of PAV and NAVA over conventional ventilation have been demonstrated in infants with a variety of postnatal ages in previous studies. Targeted tidal volumes of between 5 and $7 \mathrm{mls} / \mathrm{kg}$ were used, as studies have shown chronically ventilated infants may require $7 \mathrm{mls} / \mathrm{kg}$ $[29,30]$ and in the latter study (30) to reduce the work of breathing. It could be suggested that in babies with BPD 2hour epochs may not be sufficient to demonstrate changes in oxygenation. Previous studies, however, have demonstrated changes in oxygenation using both modes for shorter epochs of 45-60 min [5, 6, 14]. Indeed, we were able to demonstrate improved oxygenation over baseline settings for both PAV and NAVA using $2 \mathrm{~h}$ epochs and differences in the two modes with regard to the A-a gradient. In one study [12], 12-h periods were used, but the order was not randomised. Although there were no significant differences in blood gases between NAVA and pressure-regulated volume control (PRVC), neural apnoeas were only seen during PRVC, and less fentanyl was administered during NAVA (12).

In conclusion, we have found no significant differences in the "OI" after $2 \mathrm{~h}$ of support by PAV or NAVA but both significantly improved the OI compared to baseline ventilation. Other indices, as the 'A-a' gradient and SF ratio demonstrated that NAVA improved oxygenation over PAV, but the differences were relatively small.

Contributors' statement AG designed the study, analysed the data and produced the final manuscript.

$\mathrm{KH}$ collected the data, analysed the data and produced the final manuscript.

TD analysed the data and produced the final manuscript.

Funding information KAH was supported by the Charles Wolfson Charitable Trust and additionally by SLE. This research was supported by the National Institute for Health Research (NIHR) Biomedical Research Centre at Guy's and St Thomas' NHS Foundation Trust and King's College London. The views expressed are those of the authors and not necessarily those of the NHS, the NIHR or the Department of Health. The Stephanie ventilator (PAV) and the Macquet Servo-n ventilator (NAVA) were loaned to us.

\section{Compliance and ethical standards}

All procedures performed in studies involving human participants were in accordance with the ethical standards of the institutional and/or national research committee and with the 1964 Helsinki declaration and its later amendments or comparable ethical standards.

Conflict of interest Professor Greenough has held grants from various manufacturers (Abbot Laboratories, MedImmune) and ventilator manufacturers (SLE). Professor Greenough has received honoraria for giving lectures and advising various manufacturers (Abbot Laboratories, MedImmune) and ventilator manufacturers (SLE). Professor Greenough is currently receiving a non-conditional educational grant from SLE.

Informed consent Parents gave informed written consent 
Open Access This article is licensed under a Creative Commons Attribution 4.0 International License, which permits use, sharing, adaptation, distribution and reproduction in any medium or format, as long as you give appropriate credit to the original author(s) and the source, provide a link to the Creative Commons licence, and indicate if changes were made. The images or other third party material in this article are included in the article's Creative Commons licence, unless indicated otherwise in a credit line to the material. If material is not included in the article's Creative Commons licence and your intended use is not permitted by statutory regulation or exceeds the permitted use, you will need to obtain permission directly from the copyright holder. To view a copy of this licence, visit http://creativecommons.org/licenses/by/4.0/.

\section{References}

1. Fischer HS, Buhrer C (2013) Avoiding endotracheal ventilation to prevent bronchopulmonary dysplasia: a meta-analysis. Pediatrics 132:e1351-e1360

2. Schulze A (2007) Respiratory mechanical unloading and proportional assist ventilation in infants. Acta Paediatr 91:19-22

3. Stein H, Firestone K (2014) Application of neurally adjusted ventilatory assist in neonates. Semin Fetal Neonatal Med 19:60-69

4. Stein H, Firestone K, Rimensberger PC (2012) Synchronized mechanical ventilation using electrical activity of the diaphragm in neonates. Clin Perinatol 39:525-542 264

5. Schulze A, Gerhardt T, Musante G, Schaller P, Claure N, Everett R, Gomez-Marin O, Bancalari E (1999) Proportional assist ventilation in low birth weight infants with acute respiratory disease: a comparison to assist/control and conventional mechanical ventilation. $\mathrm{J}$ Pediatr 135:339-344

6. Bhat P, Patel DS, Hannam S, Rafferty GF, Peacock JL, Milner AD, Greenough A (2015) Crossover study of proportional assist versus assist control ventilation. Arch Dis Child Fetal Neonatal Ed 100: F35-F38

7. Schulze A, Rieger-Fackeldey E, Gerhardt T, Claure N, Everett R, Bancalari E (2007) Randomized crossover comparison of proportional assist ventilation and patient triggered ventilation in extremely low birth weight infants with evolving chronic lung disease. Neonatology 92:1-7

8. Shetty S, Bhat P, Hickey A, Peacock JL, Milner AD, Greenough A (2016) Proportional assist versus assist control ventilation in premature infants. Eur J Pediatr 175:57-61

9. Bosma KJ, Read BA, Bahrgard Nikoo MJ, Jones PM, Priestap FA, Lewis JF (2016) A pilot randomized trial comparing weaning from mechanical ventilation on pressure support versus proportional assist ventilation. Crit Care Med 44:1098-1108

10. Chen Z, Luo F, Ma XL, Lin HJ, Shi LP, Du LZ (2013) Application of neurally adjusted ventilatory assist in preterm infants with respiratory distress syndrome. Zhongguo Dang Dai Er Ke Za Zhi 15: 709-712

11. Lee J, Kim HS, Sohn JA, Lee JA, Choi CW, Kim EK, Kim BI, Choi JH (2012) Randomized crossover study of neurally adjusted ventilatory assist in preterm infants. J Pediatr 161:808-813

12. Longhini F, Ferrero F, De Luca D, Cosi G, Alemani M, Colombo D, Cammarota G, Berni P, Conti G, Bona G, Della Corte F, Navalesi P (2015) Neurally adjusted ventilatory assist in preterm neonates with acute respiratory failure. Neonatology 107:60-67

13. Stein H, Alosh H, Ethington P, White DB (2013) Prospective crossover comparison between NAVA and pressure control ventilation in premature neonates less than 1500 grams. J Perinatol 33:452-456
14. Shetty S, Hunt K, Peacock J, Ali K, Greenough A (2017) Crossover study of assist control ventilation and neurally adjusted ventilatory assist. Eur J Pediatr 176:509-513

15. Kallio M, Koskela U, Peltoniemi O, Kontiokari T, Pokka T, SuoPalosaari M, Saarela T (2016) Neurally adjusted ventilatory assist (NAVA) in preterm newborn infants with respiratory distress syndrome - a randomized controlled trial. Eur J Pediatr 175: $1175-1183$

16. Steinhorn R, Davis JM, Gopel W, Jobe A, Abman S, Laughon M, Bancalari E, Aschner J, Ballard R, Greenough A et al (2017) Chronic pulmonary insufficiency of prematurity: developing optimal endpoints for drug development. J Pediatr 191:15-21

17. Patel DS, Rafferty GF, Hannam S, Lee S, Milner AD, Greenough A (2010) In vitro assessment of proportional assist ventilation. Arch Dis Child Fetal Neonatal Ed 95:F331-F337

18. Akoumianaki E, Prinianakis G, Kondili E, Malliotakis P, Georgopoulos D (2014) Physiologic comparison of neurally adjusted ventilator assist, proportional assist and pressure support ventilation in critically ill patients. Respir Physiol Neurobiol 203:82-89

19. Schmidt M, Kindler F, Cecchini J, Poitou T, Morawiec E, Persichini R, Similowski T, Demoule A (2015) Neurally adjusted ventilatory assist and proportional assist ventilation both improve patientventilator interaction. Crit Care 19:56

20. Hunt KA, Dassios T, Ali K, Greenough A (2018) Prediction of bronchopulmonary dysplasia development. Arch Dis Child Fetal Neonatal Ed 103:F598-F599

21. Hird M, Greenough A, Gamsu H (1990) Gas trapping during high frequency positive pressure ventilation using conventional ventilators. Early Hum Dev 22:51-56

22. Migdal M, Dreizzen E, Praud JP, Vial M, Dehan M, Chambille B, Gaultier C (1987) Compliance of the total respiratory system in healthy preterm and full-term newborns. Pediatr Pulmonol 3:214-218

23. Chowdhury O, Bhat P, Rafferty G, Hannam S, Milner AD, Greenough A (2016) In vitro assessment of the effect of proportional assist ventilation on the work of breathing. Eur J Pediatr 175:639-643

24. Schulze A, Rich W, Schellenberg L, Schaller P, Heldt GP (1998) Effects of different gain settings during assisted mechanical ventilation using respiratory unloading in rabbits. Pediatr Res 44:132138

25. Jobe AH, Bancalari E (2001) NICHD / NHLBI / ORD workshop summary. Am J Respir Crit Care Med 163:1723-1729

26. Yildizdaș D, Yapicioğlu H, Yilmaz HL, Sertdemir Y (2004) Correlation of simultaneously obtained capillary, venous, and arterial blood gases of patients in a paediatric intensive care unit. Arch Dis Child 89:176-180

27. McLain BI, Evans J, Dear PR (1988) Comparison of capillary and arterial blood gas measurements in neonates. Arch Dis Child 63: 743-747

28. Grizelj R, Bojanic K, Pritisanac E, Luetic T, Vukovic J, Weingarten TN, Schroeder DR, Sprung J (2016) Survival prediction of highrisk outborn neonates with congenital diaphragmatic hernia from capillary blood gases. BMC Pediatr 16:114

29. Kezsler M, Nassabeh-Montazami S, Abubakar K (2009) Evolution of tidal volume requirement during the first 3 weeks of life in infants $<800 \mathrm{~g}$ ventilated with volume guarantee. Arch Dis Child Fetal Neonatal Ed 94:F279-F282

30. Hunt KA, Dassios T, Ali K, Greenough A (2019) Volume targeting levels and work of breathing in infants with evolving or established bronchopulmonary dysplasia. Arch Dis Child Fetal Neonatal Ed 104:F46-F49

Publisher's note Springer Nature remains neutral with regard to jurisdictional claims in published maps and institutional affiliations. 